\title{
The Importance of Viscoplastic Strain Rate in the Formation of Center Cracks during the Start-Up Phase of Direct-Chill Cast Aluminum Extrusion Ingots
}

\author{
M. M'HAMDI, S. BENUM, D. MORTENSEN, H.G. FJÆR, and J.-M. DREZET \\ A comparison of experimental observations and computer simulations shows that trends in the occur- \\ rence and severity of center cracks in direct-chill (DC) cast ingots due to different initial casting speed \\ histories may best be explained by the changes in viscoplastic strain rate close to the center of the base \\ of the ingot. The thermomechanical histories of five ingots were simulated and correlations between \\ stresses, strains, strain rates, and liquid pressure drops due to feeding restrictions were considered.
}

\section{INTRODUCTION}

THE start-up period of the direct-chill (DC) casting process of extrusion ingots is the most critical phase for the formation of hot tears. The hot tearing tendency during this period depends on a number of process parameters. Increasing the casting speed, for example, increases the hot tearing tendency, leading to larger amounts of scrap to be remelted. In some cases, the cracks continue to extend through the entire process, and the ingot must be rejected.

A lot of work has been done in order to understand the formation of hot tears, and a number of theories and criteria have been proposed in the literature. These studies agree that hot tearing occurs at the last stages of solidification when the fraction of solid is close to one. ${ }^{[1]}$ They also emphasize the role of strain accumulation ${ }^{[2]}$ and tensile stresses to which the material is subjected when it is still in the mushy state. ${ }^{[3,4]}$ These strains and stresses build up due to thermally-induced deformation, which arises owing to non-uniform cooling conditions throughout the casting. Liquid feeding due to solidification shrinkage and tensile deformation, which can be related to the hydrostatic pressure in the liquid, is also an important factor since no hot tear can form if liquid feeding is available. ${ }^{[5,6]}$ Furthermore, experimental studies of hot tearing formation during the start-up period of the DC casting process have established the effect of various process parameters. In addition to the casting speed, ${ }^{[7]}$ parameters such as grain refinement, starting block material and shape, and water cooling are also known to have an effect on the hot tearing tendency. ${ }^{[8,9]}$ Recent two-phase models $s^{[10,11]}$ attempt to quantify the interactions between liquid feeding and thermally-induced deformation in the mushy zone.

The purpose of the present work is to identify, by comparison between experimental observations and computer simulation, a physical quantity whose variation could best

M. M'HAMDI, Research Scientist, is with SINTEF Materials Technology, N-0314 Oslo, Norway. Contact e-mail:mohammed.mhamdi@sintef.no S. BENUM, Senior Research Scientist, is with Hydro Aluminium, R\&D Sunndalsøra, N-6600 Sunndalsøra, Norway. D. MORTENSEN and H.G. FJ/ER, Principal Research Scientists, are with the Department of Process and Fluid Flow Technology, N-2027 Kjeller, Norway. J.-M. DREZET, Senior Scientist, is with École Polytechnique Fédérale de Lausanne, CH-1015 Lausanne, Switzerland, and Calcom SA, CH-1015 Lausanne, Switzerland.

Manuscript submitted January 3, 2002. explain the observed trends in center cracks during the start-up phase of DC cast round extrusion ingots. For this purpose, a series of real-scale casting trials with varying starting conditions were carried out. The crack lengths have been measured for all trials. The casting conditions and the experimental results, including temperature measurements in the starting block and in the ingot, are presented in Section II. The trials were accompanied by numerical simulations using coupled heat transfer, fluid flow, and thermomechanical models. The simulation work and boundary conditions are described in Section III. The goal of the modeling work is to interpret the casting trials based on the simulation results. In Section IV, quantities usually associated with hot tearing, such as strains and stresses in the solid, the pressure in the liquid, and their correlation to the experimental results are discussed.

\section{CASTING TRIALS}

Five casting trials with 228-mm-diameter round extrusion ingots were performed. The geometry of the ingot is plotted in Figure 1. The cast material is an AA6060 type alloy. Initially, the starting block is inside the mold. The liquid metal is poured into the open mold from the top. Solidification starts over the surface of the starting block and along the walls of the mold. When the formed solid is sufficiently strong to hold the liquid metal inside, the steel starting block is lowered at the casting speed. As soon as the ingot emerges below the mold, water impinges directly on the surface of the casting. As can be seen in Figure 1, the starting block has a cone shape. Such a cone shape was suggested by Jensen and Schneider ${ }^{[8,9]}$ in order to reduce the susceptibility for hot tearing in the start-up phase.

The casting equipment used was a standard Hycast Gas Cushion system with modified bottom blocks. The casting speed is the only process parameter varied during the startup period of these trials (Figure 2). For trial 1, a constant speed of $130 \mathrm{~mm} / \mathrm{min}$ was used. Trial 2 was started with a casting speed of $130 \mathrm{~mm} / \mathrm{min}$ and then the speed was lowered to $80 \mathrm{~mm} / \mathrm{min}$ after $50 \mathrm{~mm}$ of cast length. The speed was later increased to $110 \mathrm{~mm} / \mathrm{min}$ after $150 \mathrm{~mm}$ of cast length. For trial 3, a constant casting speed of $110 \mathrm{~mm} / \mathrm{min}$ was used for the entire start-up phase. Trials 4 and 5 were started at the same casting speed of $80 \mathrm{~mm} / \mathrm{min}$, which was 


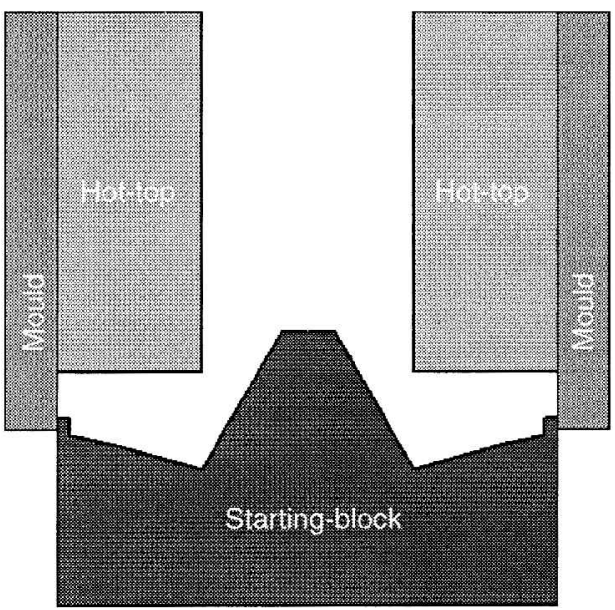

(a)

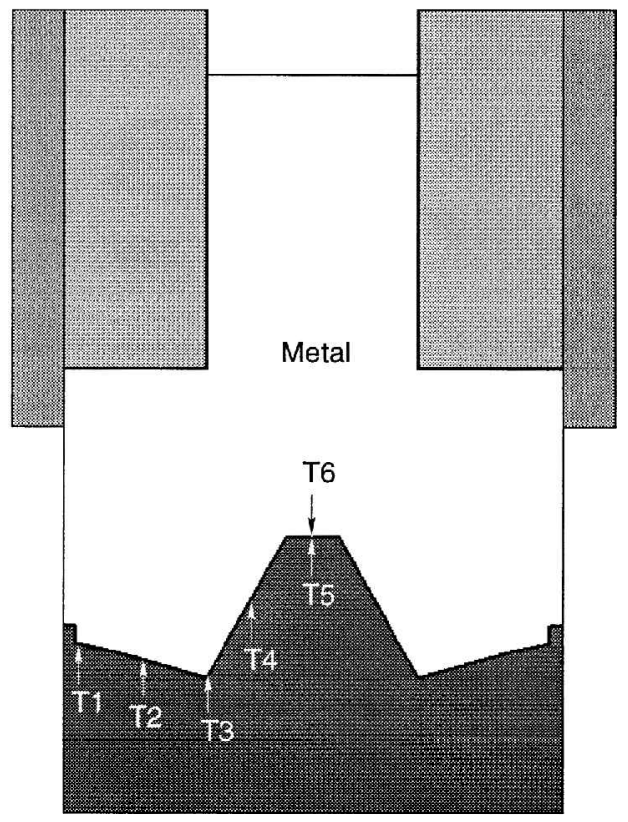

(b)

Fig. 1-(a) Initial relative positions of the domains and (b) later after the start of the trial. The positions of the thermocouples in the starting block and aluminum ingot are also shown in figure. Thermocouples 1 through 5 are placed $1 \mathrm{~mm}$ below the surface of the starting block, while thermocouple 6 is placed in the extrusion ingot $2 \mathrm{~mm}$ above the surface of the starting block.

increased linearly to $110 \mathrm{~mm} / \mathrm{min}$ from 0 to $150 \mathrm{~mm}$ of cast length for trial 4, and from 50 to $150 \mathrm{~mm}$ of cast length for trial 5. The durations of the initial filling periods were $24,22,23,17$, and 24 seconds for trials 1 through 5, respectively.

During the trials, the temperature variations were measured by thermocouples placed in the positions indicated in Figure 1. The melt temperature was measured by an additional thermocouple placed just above the inlet to the mold. The metal was grain refined with a commercial Al-5 wt pct Ti-1 wt pet B grain refiner with an amount of $2 \mathrm{~kg} / \mathrm{ton}$ in the start-up phase and less than $1 \mathrm{~kg} / \mathrm{ton}$ in the stationary period. The metal temperature at the inlet of the mold was aimed to be in the range from $700{ }^{\circ} \mathrm{C}$ to $720{ }^{\circ} \mathrm{C}$.

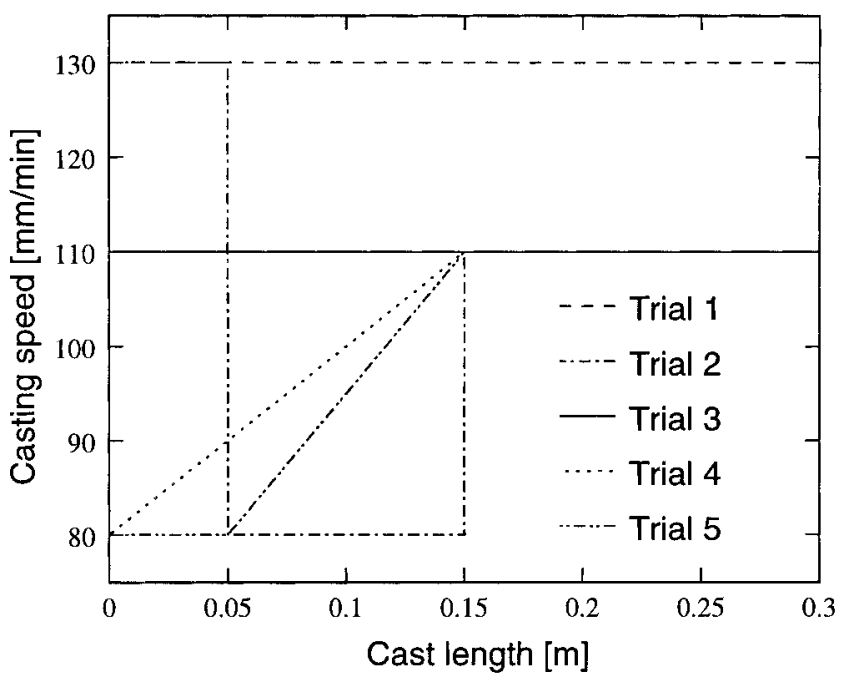

Fig. 2-Evolution of the casting speed as a function of the cast length for trials 1 through 5 .

Table I. Average Measured Starting Crack Lengths for Trials 1 through 5

\begin{tabular}{lccccr}
\hline Trial & 1 & 2 & 3 & 4 & 5 \\
\hline Crack length $(\mathrm{mm})$ & $\begin{array}{l}\text { entire } \\
\text { ingot }\end{array}$ & 58 & 214 & 0 & 0 \\
\hline
\end{tabular}

\section{A. Length of the Starting Cracks}

For each trial condition 1 to 5, ten castings have been performed simultaneously on the same casting table in order to obtain statistically representative results. After the castings, the length of the hot tears was measured using an ultrasonic device. All castings performed in the conditions of trial 1 resulted in vertical cracks starting from the bottom of the ingot and extending to the full ingot length, which indicates that the steady-state casting speed was too high to achieve a closure of the starting cracks. Trials 2 and 3 resulted in cracks that also started from the bottom of the ingot but extended only to a certain length inside the ingot, implying that the cracks were healed when entering the steady-state conditions. All castings in the conditions of trials 4 and 5 were performed without any cracks. The average measured crack lengths for each trial condition are given in Table I. If the crack length is considered as a measure of the hot tearing tendency, as done by Spittle and Cushway ${ }^{[12]}$ and Warrington and McCartney, ${ }^{[13]}$ the trials can be ranked from highest to lowest tendency, as follows: 1, 3, 2, 4, and 5. The trials with the highest susceptibility are those for which the casting speed is the highest, i.e., trials 1 and 3. The same effect of the casting speed has been reported in References 8 and 7.

\section{B. Temperature Measurements}

The inlet melt temperature was measured and the average values are $710^{\circ} \mathrm{C}$ for trials 1 through $3,715^{\circ} \mathrm{C}$ for trial 4 , and $705^{\circ} \mathrm{C}$ for trial 5 . For comparison, the liquidus and solidus temperatures for the AA6060 alloy given by the microsegregation model ALSTRUC ${ }^{[14]}$ are $655^{\circ} \mathrm{C}$ and $555.3{ }^{\circ} \mathrm{C}$, 
respectively. The measured temperatures in the starting block (thermocouples 1 through 5) and in the center of the ingot (thermocouple 6) are given for trials 1 through 4 in Figure 3. It can be seen that the temperature measurements for the different trials are quite close. Those for trial 5 deviate only slightly from those measured for trial 4 , and therefore are not shown here. The temperature measurements were commenced as soon as the filling of the molds started. During the filling phase (about 17 to 24 seconds) the temperatures in positions 1 through 5 in the starting block increase rapidly with about the same rate. As the starting block is lowered and the water impingement starts, the measured temperatures start to decrease in positions $T_{1}$ and $T_{2}$. Maximum temperatures in position $T_{5}$ in the center of the cone are $652^{\circ} \mathrm{C}, 646^{\circ} \mathrm{C}, 639^{\circ} \mathrm{C}, 635^{\circ} \mathrm{C}$ and $636^{\circ} \mathrm{C}$ for trials 1 through 5 , respectively. In this position, the measured temperature becomes higher than the solidus temperature of the alloy after about 30 to 40 seconds and stays above it until about 100 seconds. Note that in the case of trial 1 the maximum temperature in the steel starting block is almost equal to the liquidus temperature of the alloy. For position $T_{6}$ in the ingot, the temperature increases quickly up to about $660{ }^{\circ} \mathrm{C}$ as the liquid metal heats the thermocouple. The temperature then remains stable until it starts to decrease due to the effect of the water cooling after approximately 80 seconds. At this stage, the temperature in position $T_{6}$ becomes even lower than the measured temperature in position $T_{5}$ in the start- ing block. This indicates that during all the rest of the process, the heat transfer in the center of the ingot occurs mainly in the radial direction. The measurements also suggest that for all the trials, no fully solid shells form on top of the cone during the first 100 seconds of the start-up period. This position can then behave as a hot spot where thermally induced deformation can concentrate and lead to the formation of hot tears if liquid feeding is insufficient.

\section{NUMERICAL SIMULATION}

Trials 1 through 5 have been simulated using a finite element model ALSIM ${ }^{[15]}$ for the development of time-dependent heat transfer and fluid flow during DC casting and the thermomechanical model ALSPEN. ${ }^{[16]}$ In ALSIM, forced convection is taken into account and turbulence is modeled by a low-Reynolds-number $k-\varepsilon$ model. Thermal convection is included by the Boussinesq approximation, and a Darcy force is used in the mixture momentum equation, which accounts for the interfacial friction between the solid and liquid. ${ }^{[17]}$ Shrinkage-driven flow and solute transport (macrosegregation), however, are not included in the model.

During the casting trials, the top of the cone on the starting block is initially placed above the bottom of the hot top (Figure 1). As the starting block is lowered, the uppermost
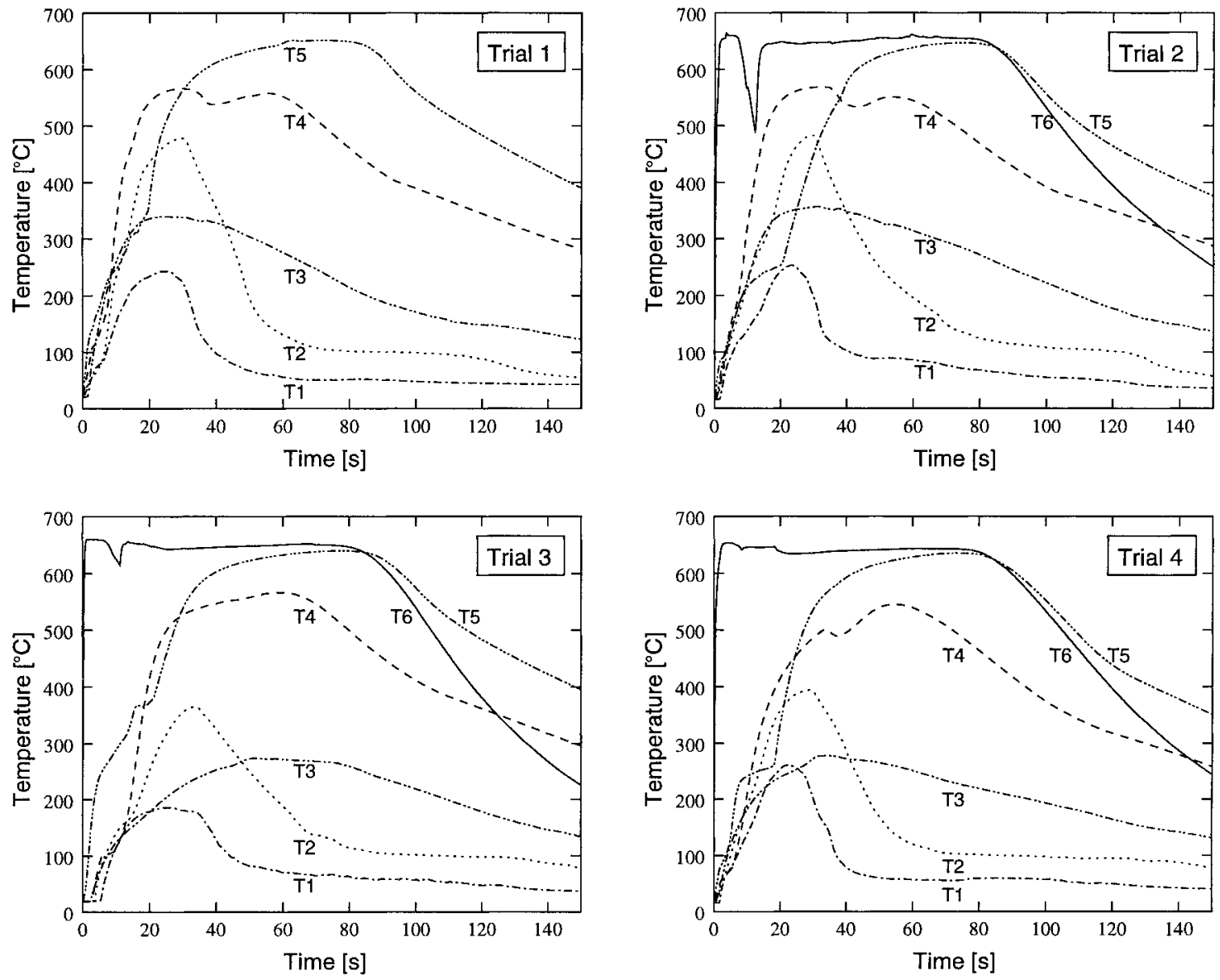

Fig. 3-Temperatures measured in the starting block $\left(T_{1-5}\right)$ and in the center of the ingot $\left(T_{6}\right)$ for trials 1 through 4 . No measurements are available at position $\mathrm{T}_{6}$ for trial 1 . 
part of the cone moves downward through the hot top area. Including this in the modeling would require a dynamic deformable mesh between the fixed hot top and the top of the moving bottom block. Such a dynamic remeshing is not implemented in the model. Due to this limitation, it has been necessary to use a slightly modified initial geometry for the ALSIM simulations. In the calculations, the height of the hot top is $18 \mathrm{~mm}$ shorter than in the real geometry, so that at the start of the simulation, the bottom of the hot top is located at the same level as the top of the starting block cone. To compensate for this limitation, an 18-mmthick ring of insulation is introduced below the hot top in order to remain as close as possible to the real heat-transfer conditions. In the model, as explained in Reference 15, a horizontal expanding row of elements is located below the hot top, which divides the domain into an Eulerian subdomain on the top and a mixed Eulerian-Lagrangian subdomain below. Moreover, because of the axisymmetric form of the ingot, the problem is reduced to two dimensions and only half of the domain plotted in Figure 1, including the hot top, the mold, the ingot, and the starting block is used in the simulation.

Thermally-induced deformations in the ingot are calculated using the finite element model ALSPEN. ${ }^{[16]}$. The solution domain for the thermomechanical calculation is only the part of the ingot that is considered to behave as a solid, i.e., where the temperature is predicted to be below a given coherency temperature, $T_{\text {coh. }}$. For the AIMgSi alloy AA6060 studied in the present work, $T_{\text {coh }}$ has been set to $641{ }^{\circ} \mathrm{C}$, which corresponds to a fraction of solid equal to 0.8 . This isotherm defines the position of the uppermost boundary of the solution domain for ALSPEN. Above this boundary, the metal is assumed to behave as a liquid, which acts with a hydrostatic pressure. In the solution domain, the material is described as an elasticviscoplastic material. The temperature-dependent material parameters used in the constitutive equations for thermal and elastic strains are extracted from Mondolfo, ${ }^{[18]}$ while the parameters for the constitutive equation for the viscoplastic strain rate are based on the experimental work of Nedreberg ${ }^{[7]}$ and are given in Reference 16. Investigations of the mechanical properties of various aluminum alloys in the mushy state ${ }^{[19,20,21]}$ have revealed that the flow stress decreases significantly with an increasing fraction of liquid. To account for this effect, though in a rather ad-hoc manner, the constitutive equation for the viscoplastic flow in the solid is modified. The flow stress in the mushy zone, $\sigma_{\text {mush }}$, is computed simply by multiplying the flow stress for the solid, $\sigma_{\text {sol }}$, with a function decreasing exponentially with the liquid fraction $g_{l}$, i.e., $\sigma_{\text {mush }}=\exp \left(-k g_{l}\right) \sigma_{\text {sol }}$. In this work, the mushy zone factor, $k$, has been given a value of 20 * $^{*}$

*An important uncertainty in the thermomechanical modeling is due to the lack of reliable data for the coherency temperature and constitutive equations for the viscoplastic behavior of the mushy zone. In order to study the sensitivity of the results to a change of the employed values, a case study has been carried out in which the coherency temperature, $T_{\text {coh }}$, and the mushy zone factor, $k$, have been varied. Although changing these values resulted in quantitatively different computed stresses and strains, qualitatively, the same trends are obtained, and the conclusions of Section IV are unchanged.

\section{A. Thermal Boundary Conditions}

The description and the numerical values of the applied heat-transfer coefficients for the heat transfer between the ingot, the mold, and the water cooling are provided in Reference 15 . Here, we will focus mainly on the heat-transfer boundary condition between the ingot and the starting block. This boundary requires a special treatment because of the contact resistance between the cast metal and the bottom block material, as well as the formation of an air gap due to the butt-curl effect.

The influence of calculated displacements and pressures on the thermal boundary conditions between the ingot and the bottom block are taken into account by coupling the ALSIM and ALSPEN models, as explained in Reference 22. As long as the temperature of a given node in the ingot bottom surface is higher than $T_{\text {coh }}$, a good contact is assumed between the ingot and the starting block, and a constant heat-transfer coefficient, $h$, is applied. When the temperature is lower than $T_{\text {coh }}$, the heat-transfer coefficient becomes dependent on both the local gap size calculated from the displacement field and the estimated contact pressure. ${ }^{[22]}$ If the air gap size is less than $0.2 \mathrm{~mm}$, the heat-transfer coefficient, $h_{g, 1}$ is assumed to depend on the local surface temperature of the ingot, $T_{s}$, and the normal pressure, $p_{n}$. If the calculated gap size is larger than $0.2 \mathrm{~mm}$, the heat-transfer coefficient, $h_{g, 2}$ is calculated from the contributions from conduction through the air, $h_{\text {cond }}$, radiation, $h_{\text {rad }}$, and an initial heat-transfer coefficient representing the insulating effect of lubrication, $h_{\text {init }}$. In order to avoid a sharp transition between $h_{g, 1}$ and $h_{g, 2}$ when an air gap has formed, the applied heat-transfer coefficient, $h$, is a smooth function of both coefficients, as shown in Table II. Vertical forces counterbalancing the total weight of the ingot are distributed underneath the ingot. The local contact pressure $p_{n}$ is estimated from the calculated gap size and the weight of the ingot, emulating an elastic response from the starting block. This simplified treatment of the boundary condition enables us to incorporate a temperature and pressure dependency in the contact heat transfer.

Table II. Heat-Transfer Coefficients between Ingot and Starting Block

\begin{aligned} & \hline$T>T_{\text {coh }} \quad h= 3000 \mathrm{~W} / \mathrm{m}^{2} \mathrm{~K} \\ & T<T_{\text {coh }} \quad h= \frac{1}{2} h_{g, 1}\left(1+\tanh \left(\frac{d_{\min }-d}{d_{\mathrm{m}}}\right)\right) \\ & \quad+\frac{1}{2} h_{g, 2}\left(1+\tanh \left(\frac{d-d_{\text {min }}}{d_{\mathrm{m}}}\right)\right) \\ &$ where $d$ is the air gap size,$d_{\text {min }}=0.2 \mathrm{~mm}$ and \\ &$d_{\mathrm{m}}=0.1 \mathrm{~mm} \\ & h_{g, 1}=a_{1}\left(T_{\mathrm{coh}}-T_{s}\right)^{a_{2}} p_{n}^{a_{3}} \\ &$ where $a_{1}=200 \mathrm{~W} / \mathrm{m}^{2} K^{1+a_{2}} \mathrm{~Pa}^{a_{3}}, a_{2}=-0.5 \\ &$ and $a_{3}=0.5 \\ & h_{g, 2}=\frac{1}{1 /\left(h_{\text {cond }}+h_{\text {rad }}\right)+1 / h_{\text {init }}} \\ &$ where $h_{\text {init }}=3000 \mathrm{~W} / \mathrm{m}^{2} \mathrm{~K}\end{aligned}$




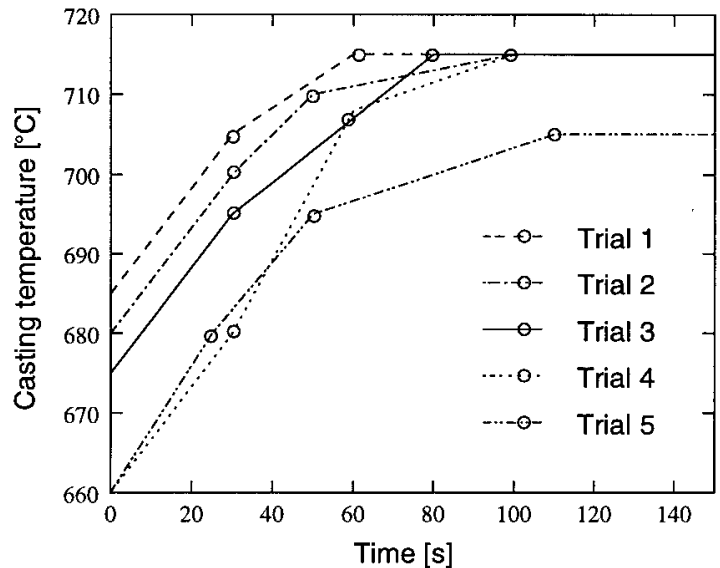

(a)

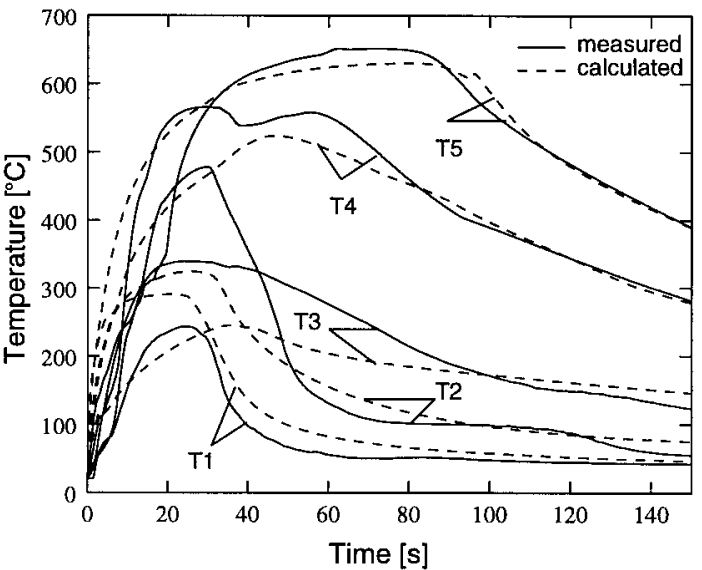

(b)

Fig. 4-(a) Measured casting temperatures (dotted) as a function of time for trials 1 through 5, and (b) comparison between calculated and measured temperatures at positions 1 through 5 for trial 1 .

Table III. Thermophysical Properties of the AA6060 Alloy Used in the Simulations

\begin{tabular}{|c|c|c|c|c|c|c|c|}
\hline Element & $\mathrm{Fe}$ & $\mathrm{Si}$ & $\mathrm{Mg}$ & $\mathrm{Cu}$ & $\mathrm{Mn}$ & & \\
\hline Composition (wt pct) & 0.19 & 0.43 & 0.48 & $<0.02$ & $<0.009$ & & \\
\hline Temperature $\left({ }^{\circ} \mathrm{C}\right)$ & 655.0 & 654.2 & 653.1 & 651.6 & 644.4 & 600.0 & 555.3 \\
\hline Mass fraction of solid & 0 & 0.15 & 0.30 & 0.45 & 0.75 & 0.95 & 1 \\
\hline Specific heat (J/kg K) & 1175 & & & & & & 1165 \\
\hline Latent heat $(\mathrm{J} / \mathrm{kg})$ & $3.9910^{5}$ & & & & & & \\
\hline Thermal expansion coefficient $\left(\mathrm{K}^{-1}\right)$ & $1.210^{-4}$ & & & & & & \\
\hline Solidification shrinkage factor, $\beta$ & $6.0 \quad 10^{-2}$ & & & & & & \\
\hline
\end{tabular}

The initial temperatures of the hot top and the starting block are set to $20^{\circ} \mathrm{C}$. The measured melt temperatures as a function of time, which are shown in Figure 4(a), were used as input to the heat-transfer calculations. The heat-transfer coefficients given in Table II have been chosen so that the best fit between measured and calculated temperatures is obtained at the positions of the thermocouples. Material parameters are listed in Table III. The solidification path for the AA6060 alloy used in the heat-transfer calculations is given by the microsegregation model ALSTRUC. ${ }^{[14]}$ Typical CPU time required for the simulations shown in Section IV is 2.5 hours on a Pentium III* $800 \mathrm{MHz}$ workstation based on a grid of

*Pentium ${ }^{\circledR}$ III Processor is a product of Intel Corporation, Santa Clara, CA.

8670 nodes (at the end of the calculation) and a time-step of 0.06 seconds.

\section{RESULTS AND DISCUSSION}

The calculated and measured temperatures from trial 1 at positions 1 through 5 are shown in Figure 4(b). Although a fairly good agreement is found for thermocouples 1, 2, and 5 after the initial phase of about 50 seconds, the calculated values are lower than the measurements for positions 3 and 4 . The differences between the measurements and the calculations are due to the lack of the hot stream impingement on the top of the cone during the initial mold filling, which is not included in the calculation, and the complexity of the heat-transfer conditions when an air gap forms between the ingot and the starting block. It should be noted that the measurements show erratic variations during the initial filling period. It is therefore not expected to find an exact match between measured and calculated temperatures. The aim was to find approximately the same thermal profiles in the bottom block in order to have good confidence in the applied heat-transfer conditions between the ingot and the bottom block.

\section{A. Mushy Zone Evolution}

The evolution of the temperature field as a function of time is plotted in Figure 5 for trial 1. Solidification of the metal on the top of the cone does not start until about $50 \mathrm{sec}-$ onds after the start of the casting. It takes about 50 seconds more for the solidus isotherm to reach the top of the cone. During the first 50 seconds, the temperature on the top of the cone increases to reach $600{ }^{\circ} \mathrm{C}$, after which the cone does not significantly affect the temperature field in the liquid metal above the cone. The temperature difference between the two materials is too small for the starting block to act as a significant cooling medium. The heat transfer occurs mainly in the radial direction and the temperature in the metal on top of the cone stays at a stable value until the solidus isotherm starts to approach the center. From the simulations, it is found that the isotherms become nearly vertical on top 

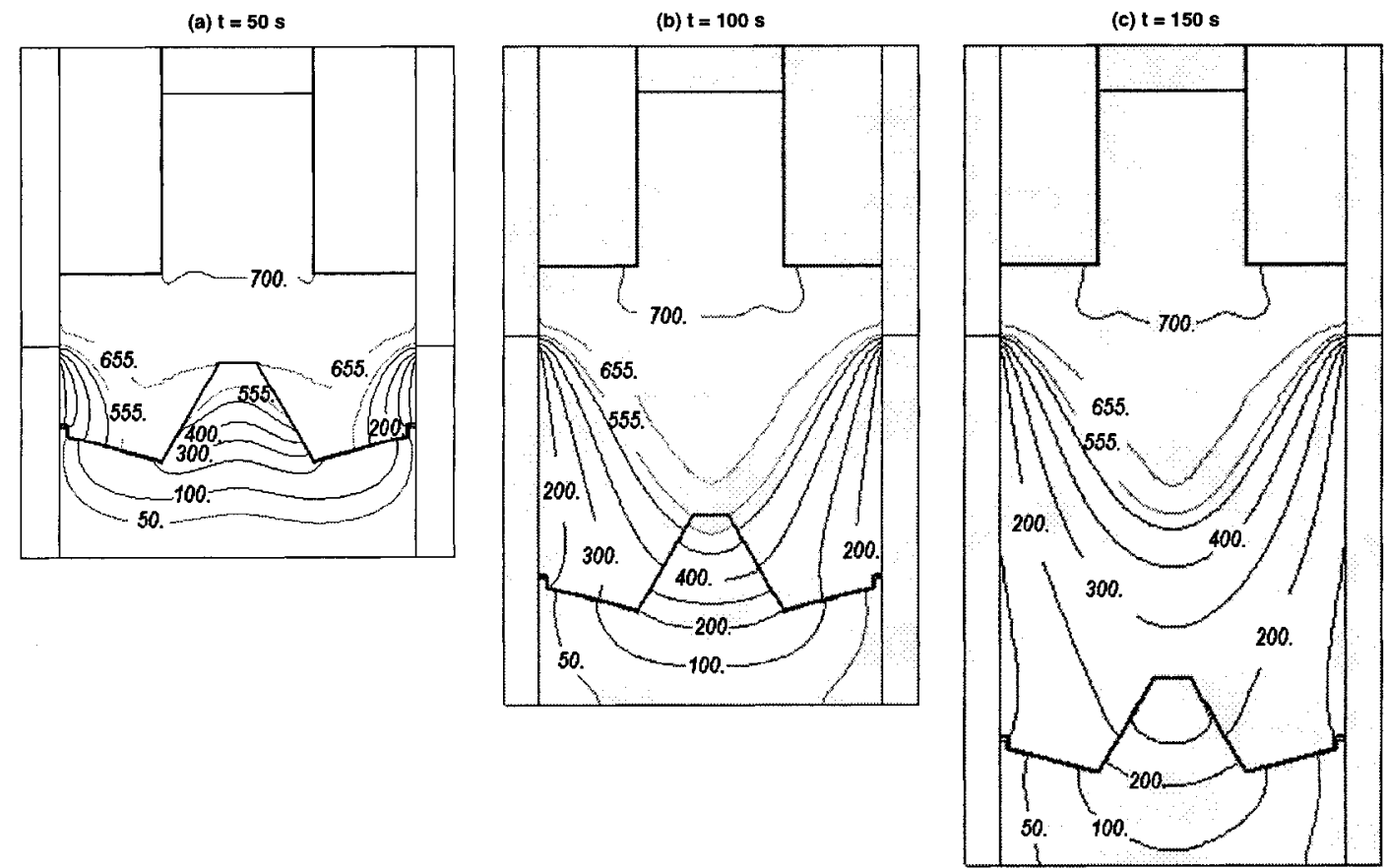

Fig. 5--Temperature field in the ingot and the starting block during the start-up period at $(a) t=50 \mathrm{~s}$, when the liquidus isotherm reaches the top of the starting block cone; at $(b) \mathrm{t}=100 \mathrm{~s}$, just before the sump leaves the top of the cone; and at $(c) t=150 \mathrm{~s}$, when the mushy zone enters the steady-state conditions. The extent of the mushy zone is given by the positions of the liquidus and solidus isotherms at $655^{\circ} \mathrm{C}$ and $555.3{ }^{\circ} \mathrm{C}$, respectively.

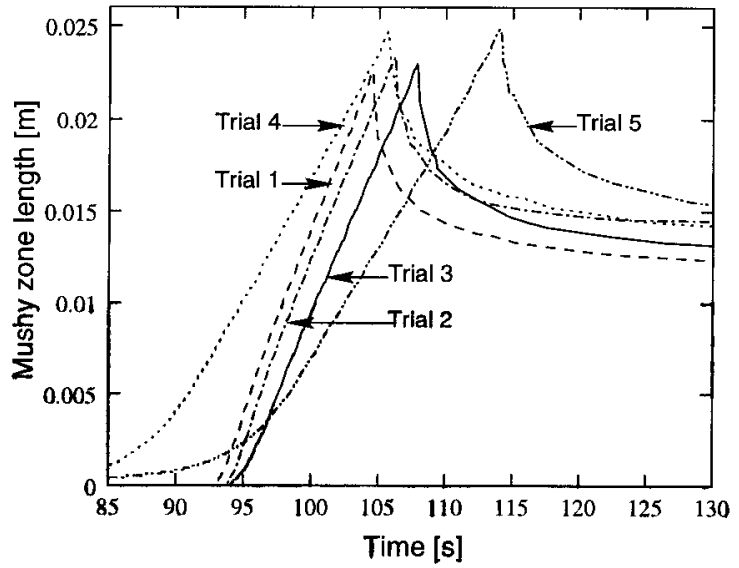

(a)

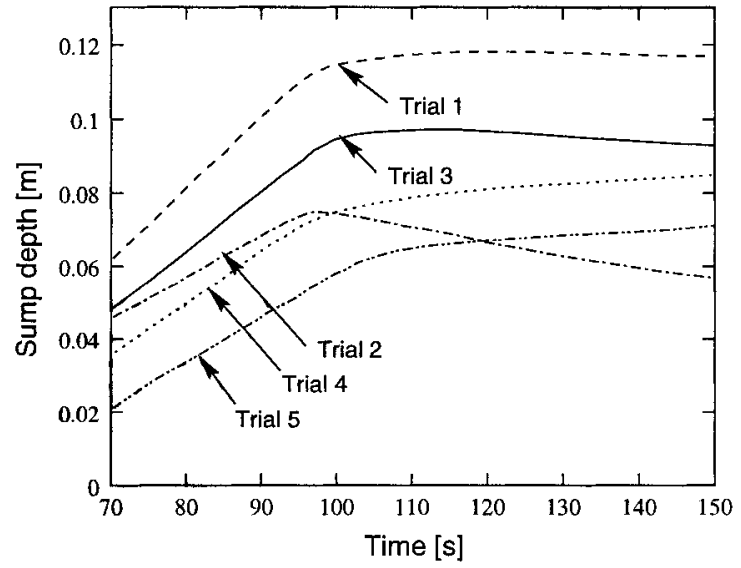

(b)

Fig. 6-Calculated (a) mushy zone length and $(b)$ sump depth along the centerline as a function of time for trials 1 through 5.

of the cone, as seen in Figure 5(b) for the solidus isotherm. At 150 seconds, the temperature field starts approaching the steady-state conditions. It is also seen that the length of the mushy zone along the centerline reaches a maximum just before the solidus isotherm leaves the cone, i.e., when the solidification fronts meet on the top of the starting block.

Figure 6(a) shows the mushy zone length at the center of the ingot for trials 1 through 5. For all the trials, one can see that the depth of the sump increases quickly to reach a maximum before rapidly decreasing and entering the steady-state conditions. All maximums are reached when the fraction of solid first equals one at the contact between the ingot and the top of the cone. When the fraction of solid of the metal on top of the cone is lower than the coherency value, the material exhibits a negligible strength and the permeability of the material is still relatively high. Liquid feeding can, therefore, easily prevent the formation of hot tears. It is during the critical phase of the process, when the fraction of solid in this location is rapidly increasing to reach one, i.e., when the permeability tends toward zero, that starting cracks can nucleate in the center and propagate inside the ingot. This critical phase coincides with the time interval during which the mushy zone is about to reach its maximum length, as shown in Figure 6(a). It should also be noted that the ranking of the trials based on their cracking tendency corresponds well with their ranking based on the maximum mushy zone lengths in ascending order. The evolutions of the sump depth in Figure 6(b) reveal another interesting observation. It can be seen that the sump depth goes through a maximum for the trials that 


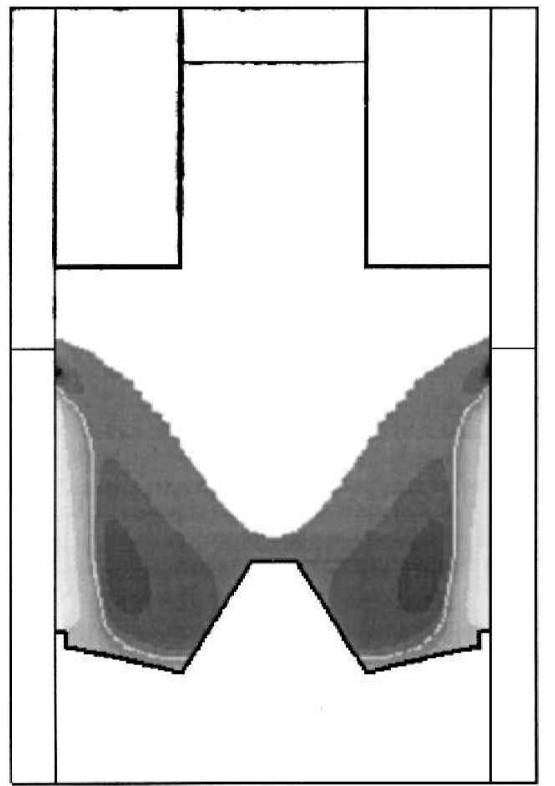

(a)

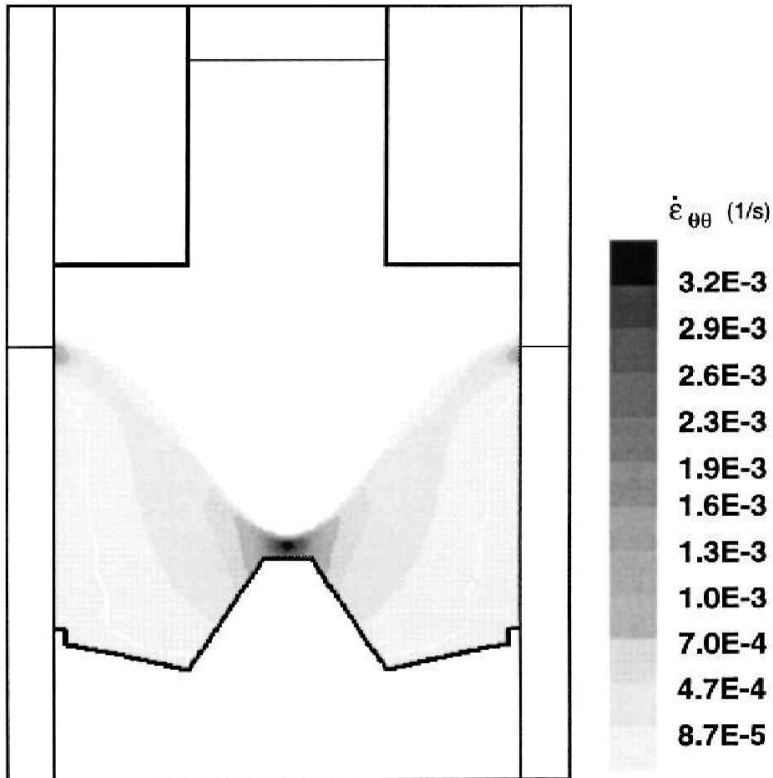

(b)

Fig. 7-Calculated (a) hoop stress and (b) hoop viscoplastic strain rate for trial 1 at $t=100 \mathrm{~s}$.

resulted in hot tears. This is in agreement with the work of Schneider and Jensen, ${ }^{[8]}$ who suggested aiming for a monotonic sump depth during the nonstationary casting phase to avoid center cracks.

\section{B. Stress and Strain Buildups}

In the simulations, the stress state and the strain rate are focused on since these quantities can be associated with the deformation of the solid skeleton in the mushy zone. As suggested elsewhere, ${ }^{[1,6,10,23]}$ these quantities are studied at a position for which the solid fraction has a given critical value here taken to be $0.95,{ }^{[23]}$ which corresponds to a temperature of $600{ }^{\circ} \mathrm{C}$. Note that this critical position does not correspond to a material point.

\section{Stress}

The calculated hoop stress $\sigma_{\theta \theta}$ and hoop viscoplastic strain rate $\varepsilon_{\theta \theta}$ are plotted in Figure 7 for trial 1 at time equal to 100 seconds, i.e., just before the sump leaves the cone, as shown in Figure 5(b). Note that symmetry causes the radial and hoop stress and strain rate components to be equal at the centerline of the ingot. Thermally-induced deformations in the already solidified shell create a tensile stress state in the center of the ingot. As shown in Figure 5(b), the insufficient heat transfer between the ingot and the starting block yields a hot spot just above the cone. At this location, the mushy zone has the lowest strength because of the elevated temperatures and the presence of grain boundary films, which leads to a significant strain concentration, as can be seen in Figure 7. Indeed, while the computed local thermal strain rate in the hot spot is about $-3 \cdot 10^{-4} \mathrm{~s}^{-1}$, the calculated hoop viscoplastic strain rate is about $3 \cdot 10^{-3} \mathrm{~s}^{-1}$, at time $t=100 \mathrm{~s}$ for trial 1 . Away from the hot spot, the computed radial strain rate decreases rapidly to almost zero. In the center, the combination of a tensile stress state, strain concentration, and the difficult liquid feeding at high fractions of solid creates a favorable situation for the formation of a hot tear.

It is commonly believed that in order for a hot tear to form, the stress must exceed a critical limit. Since starting cracks in the center of the ingot propagate in the vertical direction, it is of interest to analyze the stress components in the direction perpendicular to the crack direction. Both the radial (equal to the hoop) and the mean stress in the center of the ingot at the critical position (corresponding to a fraction of solid of 0.95) are plotted in Figure 8 as a function of the solidified length for all trials.* If the peak radial

*All quantities discussed here are plotted as a function of the solidified length, and not as a function of time. The solidified length is defined as the distance between the critical position, which corresponds to the position of the fraction of solid 0.95 , and the position of the top of the starting block in the center of the ingot. Peak values for all trials are reached at almost the same solidified length. They are, however, reached at different time points, as is the case for the depth of the mushy zone in Figure 6(a).

(or hoop) stresses are used as indicators for the hot tearing tendency, the five trials may be ranked in the sequence trials $1,3,2,4$, and 5 . Note that this ordering of the trials is in agreement with the length of the cracks for trials 1,2 and 3. Although no cracks occurred for trials 4 and 5, trial 5 should have the lowest cracking tendency since a lower or equal casting speed was used compared to trial 4 (Figure 2). This again is in agreement with the calculated maximum stresses for trial 4 , which are higher than those computed for trial 5. It should, however, be noted that all calculated peak values for the radial (or hoop) stresses, for example, range between 2.4 and $3.1 \mathrm{MPa}$, indicating relatively close stress states. This is in contrast to the measured crack lengths, which imply a larger difference in hot tearing tendency between trials 1 and 3 and between trials 3 and 2 .

It is interesting to notice that peak values of the mean stress also correlate well with the ranking based on the crack lengths. Although the Von Mises flow rule and the 


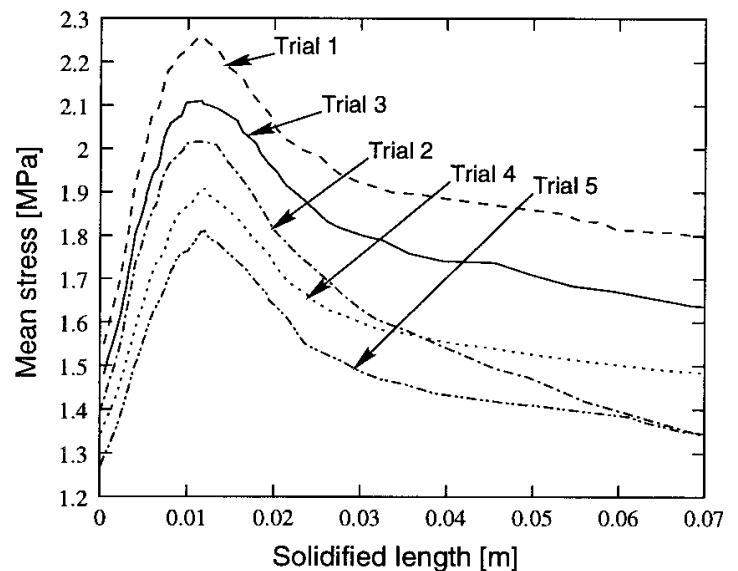

(a)

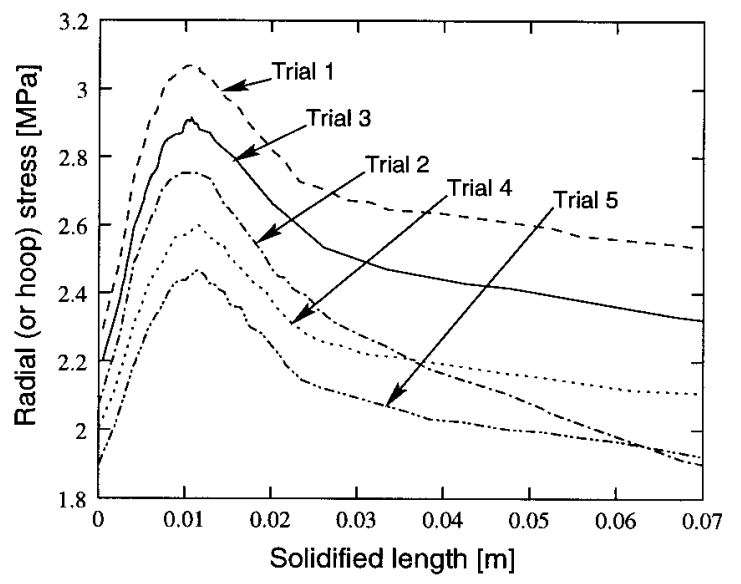

(b)

Fig. 8--Calculated (a) mean stress and (b) radial (or hoop) stress in the center of the ingot at the critical position.

viscoplastic strain rate constitutive equation used to describe the rheological behavior of the material are independent of the mean stress, work done by Martin et al. ${ }^{[24-27]}$ suggests that this quantity can also have an effect on the behaviour of the material. Martin et al. consider the mushy zone as a porous metallic material saturated with liquid, and propose constitutive equations for the material behaviour where both the first and second invariant of the stress tensor are introduced. Their approach has recently been incorporated in a two-phase model for thermally induced deformation in the mushy zone, ${ }^{[11]}$ and could serve as a basis for a better description of the mushy zone rheology.

\section{Strain Rate}

Critical accumulated strains or strain rates are also often used as criteria for the formation of hot tears. ${ }^{[6,7,28]}$ The strain rate tensor is the sum of the thermal, elastic, and viscoplastic contributions. Since elastic strains are much smaller than the viscoplastic strains in the mushy zone due to the elevated temperatures, only the viscoplastic contribution is of interest. For symmetry reasons, the radial and hoop components of the viscoplastic strain rate tensor are equal in the center of the ingot, and are both acting in a direction perpendicular to that of the crack propagation.

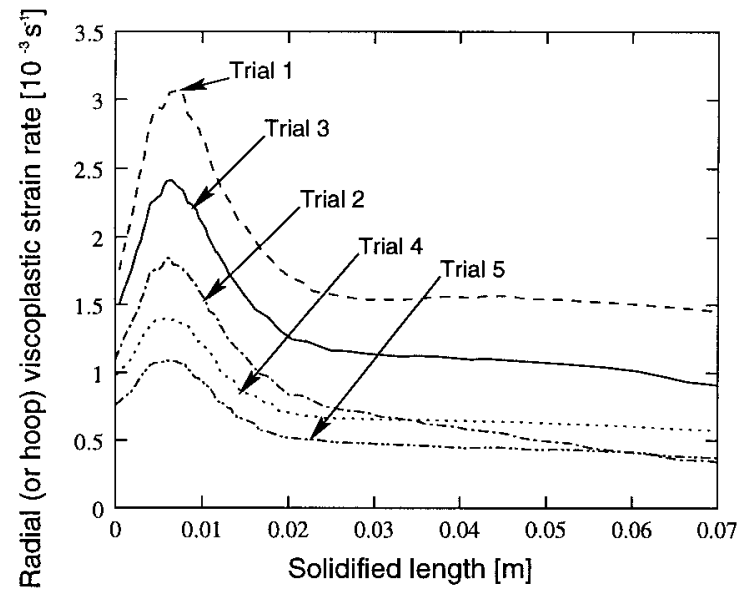

(a)

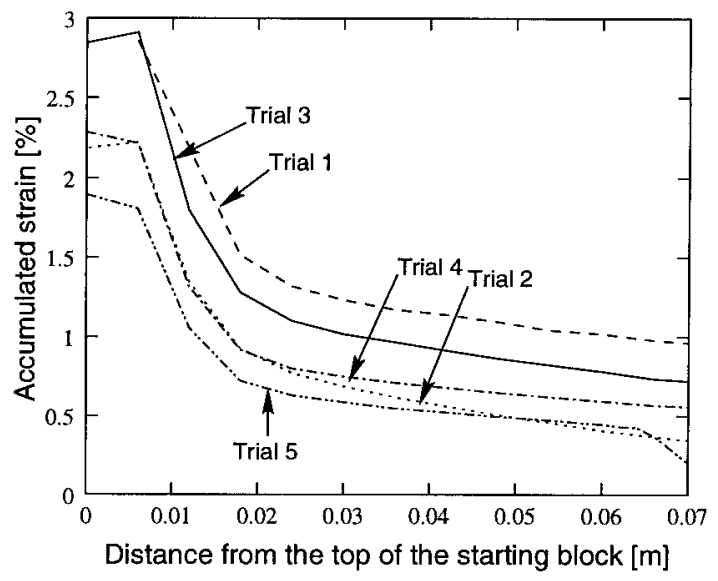

(b)

Fig. 9-Calculated (a) radial (or hoop) viscoplastic strain rate in the center of the ingot at the critical position and $(b)$ accumulated strain along the centerline for trials 1 through 5 .

The values of this quantity at the critical position in the center of the ingot are plotted in Figure 9 as a function of the solidified length for trials 1 through 5 . If peak values are used as an indicator for the hot tearing tendency, the trials can be ranked in the following sequence: $1,3,2,4$, and 5 , which is in agreement with the ranking based on the crack lengths for trials 1 through 3 . The calculated peak strain rate values are also always higher for trial 4 than for trial 5 , which is in agreement with the higher or equal casting speed of trial 4 compared to trial 5. Furthermore, in contrast to the computed stresses of Figure 8, the calculated peak values of Figure 9(a) show a significant distinction between trials 1,3 , and 2 , which is in agreement with the substantial differences in the measured crack lengths between trials 1 and 3 and trials 3 and 2 .

Figure 9(a) also shows that after the peak values are reached, the strain rate for trial 2 drops quickly to reach the same levels as for trials 4 and 5. This is not the case for trials 1 and 3 for which the strain rates remain at a higher level, with trial 1 having always larger values than trial 3 . Although the model is not valid anymore when a crack has formed, as for trials 1 through 3 , the differences in strain rate levels after the peak values, when the process is approaching the steady-state conditions, can be used as an 
indication for the magnitude of the driving force for crack propagation. The rapid decrease in strain rate level for trial 2 to the levels of trials 4 and 5 (about $5.5 \cdot 10^{-4} \mathrm{~s}^{-1}$ ), for which no cracks occurred, at $0.045 \mathrm{~m}$ of solidified length, correlates well with the small crack length for trial $2(0.058 \mathrm{~m})$. The strain rate for trial 3 reaches the same levels only after $0.25 \mathrm{~m}$ of solidified length, which again correlates well with the larger crack length for trial 3 $(0.21 \mathrm{~m})$. Although the strain rate level for trial 1 also decreases, it continues at a higher level than the other trials even when entering the steady-state conditions.

In order to study the effect of the height of the starting block cone, two additional calculations have been carried out in the conditions of trial 1 with cone heights reduced by 10 and $21 \mathrm{~mm}$, respectively. Results from these simulations, not shown here, predict substantially lower values for the strain rate than those plotted for trial 1 in Figure 9(a), implying a lower hot tearing tendency for the cases with a lower cone height. Another important parameter for the hot tearing tendency is the starting block material. A copper or an aluminium starting block, because of its higher thermal conductivity compared to steel, would reduce the hot tearing tendency by enhancing the heat transfer between the ingot and the cone, as suggested in Reference 9.

\section{Accumulated Strain}

It has also been suggested that the nucleation and propagation of hot tears can be related to some critical straining of the material when it is still in the mushy state. ${ }^{[2,7]}$ In order to check the validity of this criterion, the strain accumulated in the material in the vulnerable stage between the fractions of solid 0.9 and $0.99, \Delta \varepsilon=\varepsilon\left(g_{s}=0.99\right)-\varepsilon\left(g_{s}=0.9\right)$, has been recorded during the calculations. The values of $\Delta \varepsilon$ along the centerline of the casting are plotted in Figure 9(b) as a function of the distance from the top of the starting block. The accumulated strains are largest for the positions in the ingot close to the starting block. This is because solidification in these locations occurs while the viscoplastic strain rates are at their highest values due to strain concentration (Figure 7(b)). Away from the top of the starting block, where solidification occurs later in the process, this phenomenon is less pronounced, as seen in Figure 9(a), and the accumulated strains are significantly lower.

If the maximum accumulated strains are used as an indicator of the hot tearing tendency, trial 3 is ranked before trial 1, and trial 2 is ranked after trial 4 . The comparison with the cracking tendency based on the measured crack lengths is not as good as with the radial viscoplastic strain rates. It should be noted that the accumulated strains do not depend only on the viscoplastic strain rates, but also on the amount of time spent by the material in the vulnerable region (between fractions of solid 0.9 and 0.99 ). This time is greater for trial 4 than for trial 2 due to the slower casting speed. For this reason, trial 4 is ranked before trial 2, although the opposite ranking is obtained based on the radial strain rates of Figure 9(a).

\section{Liquid Feeding}

Although a main part of the mechanism of hot tearing formation is tensile straining of the mushy zone, ${ }^{[4]}$ no hot tear can form if liquid feeding is sufficient. As shown by
Poirier et al., ${ }^{[29]}$ a key driving force for liquid feeding is solidification shrinkage due to density difference between the liquid and the solid phase. The latter can be characterised with a shrinkage factor $\beta=\left(\rho_{l}-\rho_{s}\right) / \rho_{l}$, where $\rho_{l}$ and $\rho_{s}$ are the liquid and solid densities respectively, assumed here to be constant but not equal. An additional driving force for liquid feeding is tensile straining of the mushy zone. As explained by Niyama ${ }^{[30]}$ and by Rappaz et al., ${ }^{[6]}$ tensile stresses in the solidifying dendritic network will result in widening the volume between the grains, which in turn increases the need for liquid feeding.

Using Darcy's law to describe liquid flow, Rappaz et al. calculated the pressure drop in the mushy zone due to both solidification shrinkage, $\Delta p_{\mathrm{sh}}$, and straining of the mushy zone, $\Delta p_{\text {mec }}$. At the fractions of solid where hot tears occur, the permeability of the mushy zone is low, and the resulting total pressure drop $\left(\Delta p=\Delta p_{\mathrm{sh}}+\Delta p_{\mathrm{mec}}\right)$ is usually considered as a measure of the liquid feeding difficulties. ${ }^{[6,10]}$ For Niyama in the case of steels and Rappaz et al. in the case of aluminum columnar dendrites, a hot tear will occur when the pressure drop in the liquid is larger than a cavitation depression. In other words, the larger the pressure drop, the higher is the tendency for hot tearing. One main difference between the criteria of Niyama and Rappaz et al. is that the latter takes into account both the shrinkage and mechanical contributions, while Niyama considers only the mechanical contribution in the pressure drop.

In order to calculate $\Delta p$ in the center of the ingot, though in an approximate manner, the model proposed by Rappaz et al. and initially developed for steady-state situations has been extended to transient conditions, as outlined in the Appendix. The model is applied only along the centerline, where it is assumed that liquid feeding must compensate for both solidification shrinkage and the radial straining of the mushy zone. Since the evolution of the fraction of solid and the strain rates are known from the thermal and mechanical calculations, it is possible to evaluate both $\Delta p_{\text {sh }}$ and $\Delta p_{\text {mec }}$ (Appendix). Figure 10 shows both the shrinkage and mechanical pressure drops for trials 1 through 5 in the center of the ingot. The pressure drops are calculated between the positions of the iso-solid fractions 0.8 and 0.95 in the mushy zone.* For all the trials,

\footnotetext{
*Using a smaller fraction of solid for the upper boundary of the mushy zone does not change the results, because most of the pressure drop occurs in the last stages of solidification for the fractions of solids larger than 0.8 . However, using a fraction of solid of 0.99 for the lower boundary of the mushy zone leads to larger pressure drops, but gives qualitatively the same results. Moreover, the hydrostatic contribution, which tends to decrease the total pressure drop, is negligible compared to the mechanical and shrinkage contributions.
}

the pressure drops, after reaching their maximum values, level out quickly as the process enters the steady-state conditions. The largest values are obtained during the critical phase of the casting when the sump is about to leave the top of the starting block. As expected, trial 1 undergoes the highest pressure drops, clearly demonstrating a severe situation for liquid feeding, and the possibility of pore nucleation. Conversely, the calculated values are lowest for trial 5 for which no cracks occurred. 


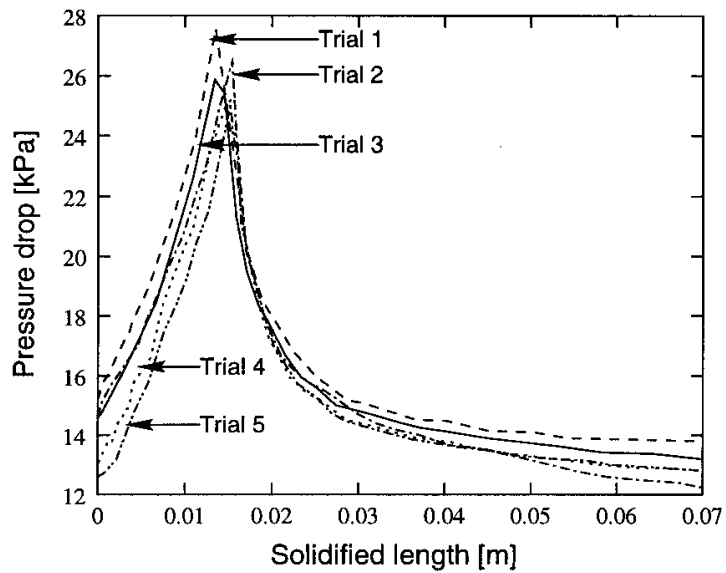

(a)

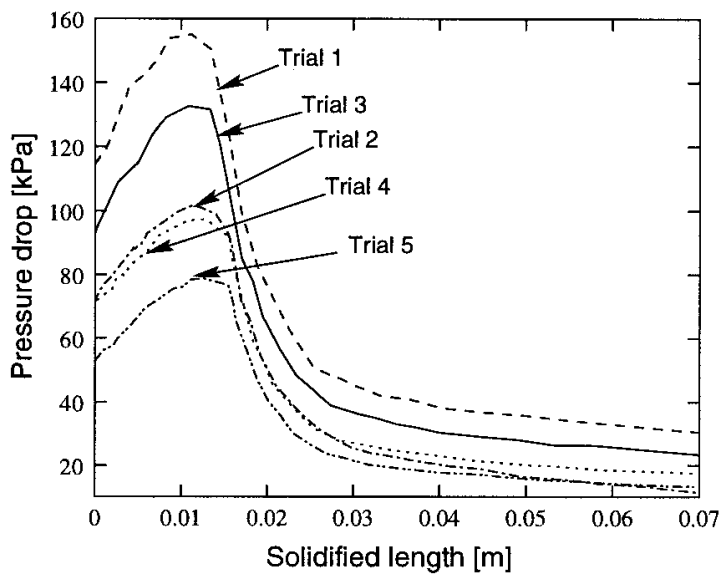

(b)

Fig. 10-Calculated (a) shrinkage and $(b)$ mechanical pressure drops in the center of the mushy zone for trials 1 through 5 .

The calculated shrinkage contributions of Figure 10(a), however, are quite close for all trials and therefore unlikely to explain the observed large variation in cracking tendency. During the critical phase of the process, the mechanical pressure drop is 3 to 6 times larger than the shrinkage contribution, revealing that most of the total pressure drop is due to the mechanical deformation of the mushy zone. This is primarily due to the severe strain concentration occurring on the top of the starting block when the solidus isotherm reaches this location (Figure 9(a)) and the need for liquid feeding to compensate for the straining of the mushy zone. If peak values of the mechanical pressure drop are used as a measure for the hot tearing tendency, the following sequence is obtained: $1,3,2,4$, and 5, in agreement with the ranking based on the measured crack lengths. The computed pressure drops for trials 2 and 4, however, are comparable, while a hot tear occurred for trial 2 but not for trial 4. Because of the relatively small shrinkage contribution, the same ranking is obtained when the maximum total pressure drop $\left(\Delta p_{\mathrm{sh}}\right.$ $\left.+\Delta p_{\text {mec }}\right)$ is used instead of the mechanical contribution alone.

It should be noted that, due to the simplified approach adopted here, the calculated mechanical pressure drops are probably overestimated, since, in addition to liquid feeding, some plastic deformation in the vertical direction also compensates for the radial straining of the mushy zone. It is also well known that grain refining reduces the tendency for hot tearing. This effect has not been studied here, and the models should be further developed to include the grain-size lengthscale.

\section{CONCLUSIONS}

From the temperature measurements and the simulations, it is shown that insufficient heat transfer between the ingot and the starting block yields a hot spot just above the cone in the center. The temperature in the cone becomes too high for it to act as a cooling medium during the critical phase of the process, i.e., when the sump is about to leave the top of the cone. From the simulation work, the following conclusions can be made.

1. Qualitatively, trends in the calculated stresses and viscoplastic strain rates acting in the perpendicular direction to the crack propagation are in good correspondence with the measured crack lengths. The calculated viscoplastic strain rate provides the best correlation with the severity of center cracks. The agreement between center cracking and the calculated accumulated strains is less good.

2. Pressure drops in the mushy zone calculated using a simple model show that the mechanical contribution is larger than the shrinkage contribution during the critical late stage of solidification. Computed pressure drops show that liquid feeding is more difficult for the trials that resulted in the formation of hot tears.

It is believed that the casting trials presented here could serve as a basis for the testing of new hot tearing criteria. One of the shortcomings of the simulations shown here is the simplified treatment of the rheology of the semisolid material. More realistic constitutive equations for the rheological behavior of the mushy zone such as those proposed in Reference 27 are clearly needed for the thermomechanical modeling.

\section{ACKNOWLEDGMENTS}

The authors thank Professor Asbjørn Mo, SINTEF (Norway), for his useful comments and suggestions during this work. The authors are also grateful to one of the reviewers for his remarks and suggestions. This research is carried out as part of the Fifth European research framework programme called Competitive and Sustainable Growth as Project No. GRD1-1999-10921 VIRCAST (The Virtual Casthouse) (Contract No. G5RD-CT-2000-00153). It includes the following partners and major subcontractors: Alusuisse Technology \& Management Ltd. (Switzerland); Calcom SA (Switzerland); Elkem Aluminum ANS (Norway); École Polytechnique Fédérale de Lausanne (Switzerland); Hoogovens Corporate Services (The Netherlands); Hydro Aluminum AS (Norway); Institute for Energy Technology (Norway); Institut National Polytechnique de Grenoble (France); Institut National Polytechnique de Lorraine (France); Norwegian University of Science and Technology (Norway); Péchiney S.A. (France); SINTEF Materials Technology (Norway); and 
VAW Aluminum AG (Germany). Funding by the European Community and by the Office Fédéral de l'Education et de la Science (Bern) for the Swiss partners is gratefully acknowledged.

\section{APPENDIX}

\section{Calculation of the Liquid Pressure Drop}

The calculation of the shrinkage and mechanical contributions to the total pressure drop in the mushy zone in the case of steady-state situations has been described in detail by Rappaz et al. ${ }^{[6]}$ The purpose of this section is to extend their approach to transient situations. As in Reference 6, it is assumed that in the one-dimensional situation of Figure 11, the flow of liquid moves along the $x$-axis only, and that the solid deforms in the transverse direction $y$. In a frame of reference attached to the starting block, the equation of mass conservation can be written as

$$
\frac{\partial}{\partial t}\left(\rho_{l} f_{l}+\rho_{s} f_{s}\right)+\frac{\partial}{\partial x}\left(\rho_{l} f_{l} v_{l, x}\right)+\frac{\partial}{\partial y}\left(\rho_{s} f_{s} v_{s, y}\right)=0
$$

Where $\rho_{k}, f_{k}, v_{k, x}$, and $v_{k, y}$ refer to the density, the volume fraction, and the velocity components of phase $k \epsilon\{s, l\}$. Introducing the shrinkage factor, $\beta=\left(\frac{\rho_{s}}{\rho_{l}}-1\right)$, and the strain rate in the transverse direction, $\varepsilon_{p}=\frac{\partial v_{s, y}}{\partial y}$, leads to the following equation:

$$
\beta \frac{\partial f_{s}}{\partial t}+\frac{\partial\left(f_{l} v_{l, x}\right)}{\partial x}+(1+\beta) f_{s} \varepsilon_{p}=0
$$

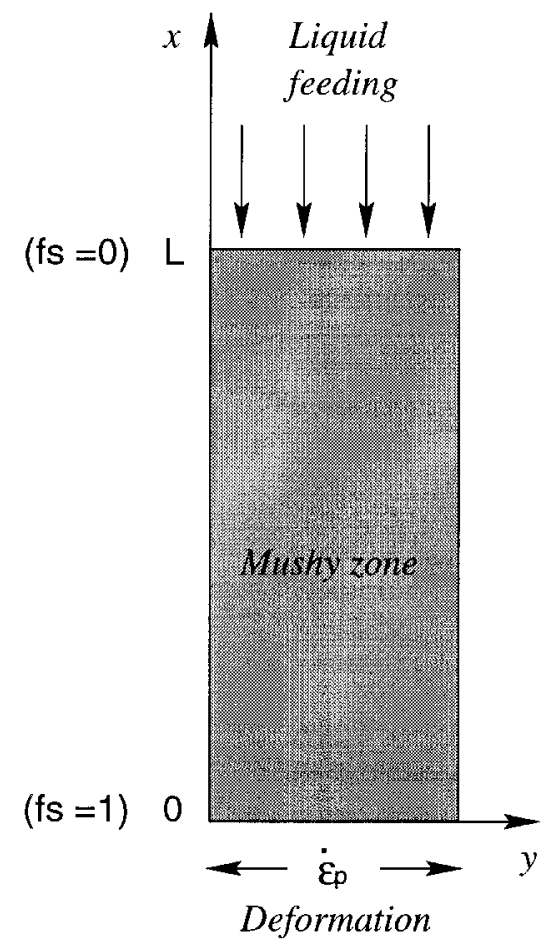

Fig. 11-Schematic illustration of the mushy zone.
Integrated over a distance $\mathrm{x}$ in the mushy zone, Eq. [2] gives

$$
\begin{gathered}
\beta \int_{0}^{x} \frac{\partial f_{s}}{\partial t} d x+g_{l} v_{l, x}+(1+\beta) \int_{0}^{x} \cdot f_{s} \varepsilon_{p} d x=C \\
\beta F+f_{l} v_{l, x}+(1+\beta) E=C
\end{gathered}
$$

with the functions $F$ and $E$ defined by

$$
\begin{aligned}
& F=\int_{0}^{x} \frac{\partial f_{s}}{\partial t} d x \\
& E=\int_{0}^{x} f_{s} \varepsilon_{p} d x
\end{aligned}
$$

The constant $C$ can be calculated from the boundary con$\operatorname{dition} f_{s}=1$ at which $v_{l, x}=0$. This leads to $C=0$. Liquid flow in the mush can be described using Darcy's law:

$$
f_{l} v_{l, x}=-\frac{K \partial_{p}}{\mu \partial x}
$$

where $K$ denotes the permeability of the mushy zone, $\mu$ the dynamic viscosity of the liquid phase, and $p$ the liquid pressure. The pressure drop between the top of the mushy zone, $L$, and any position, $x$, in the mush can be calculated by combining Eq. [2] and [7] and integrating between $x$ and $L$ :

$$
\Delta p=\beta \mu \int_{x}^{L} \frac{F}{K} d x+(1+\beta) \mu \int_{x}^{L} \frac{E}{K} d x
$$

where $\Delta p$ can then be written as the sum of two contributions: $\Delta p=\Delta p_{s h}+\Delta p_{\text {mec }}$, with

$$
\begin{gathered}
\Delta p_{s h}=\beta \mu \int_{x}^{L} \frac{F}{K} d x \\
\Delta p_{\text {mec }}=(1+\beta) \mu \int_{x}^{L} \frac{E}{K} d x
\end{gathered}
$$

where $\Delta p_{s h}$ is the contribution associated with the solidification shrinkage, while $\Delta p_{\text {mec }}$ is the contribution associated with the mechanical deformation. The permeability, $K$, is given by the Kozeny-Carman relation:

$$
K=\frac{\lambda_{2}^{2}}{180} \frac{f_{l}^{3}}{\left(1-f_{l}\right)^{2}}
$$

where $\lambda_{2}$ is the secondary dendrite arm spacing. In the axisymmetric situation of Section IV-C-C, the viscoplastic strain rate in the center of the ingot, $\varepsilon_{p}$, has to be replaced by $\varepsilon_{r r}+\varepsilon_{\theta \theta}=2 \varepsilon_{\theta \theta}$. In the calculations, $\lambda_{2}$ was set to $40 \mu \mathrm{m}$.

\section{REFERENCES}

1. T.W. Clyne and G.J. Davies: Br. Foundry, 1981, vol. 74, pp. 65-73.

2. W.S. Pellini: Foundry, 1952, pp. 125-33 and 192-99.

3. Y.F. Guven and J.D. Hunt: Cast Met., 1988, vol. 1, pp. 104-11. 
4. J. Campbell: Castings, Butterworth Heinemann, England, 1991.

5. U. Feurer: Giesserei Forschung, 1976, vol. 28, p. 75.

6. M. Rappaz, J.-M. Drezet, and M. Gremaud: Metall. Mater. Trans. A, 1999, vol. 30A, pp. 449-550.

7. M.L. Nedreberg: Ph.D. Thesis, University of Oslo, Oslos 1991.

8. W. Schneider and E.K. Jensen: in Light Metals, C.M. Bickert, ed., TMS-AIME, Warrendale, PA, 1990, pp. 931-36.

9. E.K. Jensen and W. Schneider: in Light Metals, C.M. Bickert, ed., TMS-AIME, Warrendale, PA, 1990, pp. 937-43.

10. I. Farup and A. Mo: Metall. Mater. Trans. A, 2000, vol. 31A, pp. 1461-72.

11. M.M'hamdi, A.Mo, and C.L. Martin: Metall. Mater. Trans. A, 2002, vol. 33A, pp. 2081-93.

12. J.A. Spittle and A.A. Cushway: Met. Technol. 1983, vol. 10, pp. 6-13.

13. B. Warrington and D.G. McCartney: Cast Met., 1989, vol. 2(3), pp. 135-43.

14. A.L. Dons, E.K. Jensen, Y. Langsrud, E. Trømborg, and S. Brusethaug: Metall. Mater. Trans. A, 1999, vol. 30A, pp. 2135-46.

15. D. Mortensen: Metall. Mater. Trans. B, 1999, vol. 30B, pp. 119-33.

16. H.G. Fjær and A. Mo: Metall. Trans. B, 1990, vol. 21B, pp. 1049-61.

17. B.R. Henriksen, E.K. Jensen, and D. Mortensen: in Modeling of Casting, Welding and Advanced Solidification Processes VIII, B.G. Thomas and C. Beckermann, eds., TMS, USA, 1998, pp. 623-30.

18. L.F. Mondolfo: ALUMINIUM ALLOYS, Structure and Properties, Butterworth and Co. London, 1976.

19. L. Ohm and S Engler: Giessereiforschung, 1990, vol. 42 (4), pp. 149-62.
20. J.M. Drezet and G. Eggeler: Scripta Metall. Mater., 1994, vol. 31 (6), pp. 757-62.

21. P. Wisniewski and H.D. Brody: in Modeling and Control of Casting and Welding Processes V, M. Rappaz, M. R. Özgü, and K.W. Mahi, eds., TMS, Warrendale, PA, 1991, pp. 273-78.

22. H. Fjær, D. Mortensen, A. Håkonsen, and E.A. Sørheim: Light Metals, TMS, Warrendale, PA, 1999, pp. 743-48.

23. S. Benum, D. Mortensen, and H. Fjær: in Continuous Casting, K. Ehrke and W. Schneider, eds., Wiley-VCH Verlag, Germany, 2000, pp. 54-60.

24. C.L. Martin, D. Favier, and M Suéry: Int. J. Plasticity, 1997, vol. 13 (3), pp. 215-35.

25. C.L. Martin, D. Favier, and M Suéry: Int. J. Plasticity, 1997, vol. 13 (3), pp. 237-59.

26. C.L. Martin, D. Favier, and M Suéry: Int. J. Plasticity, 1999, vol. 15, pp. 981-1008.

27. C.L. Martin, M. Braccini, and M. Suéry: Mater. Sci. Eng. A, 2000, vol. A325, pp. 293-302.

28. H.G. Fjær, E.K. Jensen, and A. Mo: Proc. 5th Int. Aluminium Extrusion Technology Seminar, R.I. Werner and V.R. Bird, eds. The Aluminum Association, Aluminum Extruders Council, USA, 1992, pp. 113-20.

29. D.R. Poirier, K. S. Yeum, and A.L. Maples: Metall. Trans. A, 1987, vol. 18A, pp. 1979-87.

30. E. Niyama: Japan-USA Joint Seminar on Solidification of Metals and Alloys, National Science Foundation, 1977, pp. 271-82. 